\title{
BMJ Analysis of 2009 pandemic influenza A/H1N1 outcomes in 19 European countries: association with completeness of national strategic plans
}

\author{
Aronrag Meeyai, ${ }^{1,2}$ Ben S Cooper, ${ }^{3,4}$ Richard Coker ${ }^{2}$
}

To cite: Meeyai $A$, Cooper BS, Coker R. Analysis of 2009 pandemic influenza $\mathrm{A} / \mathrm{H} 1 \mathrm{~N} 1$ outcomes in 19 European countries: association with completeness of national strategic plans. BMJ Open 2013;3: 002253.

doi:10.1136/bmjopen-2012002253

- Prepublication history and additional material for this paper are available online. To view these files please visit the journal online (http://dx.doi.org/10.1136/ bmjopen-2012-002253).

Received 16 November 2012 Revised 3 February 2013 Accepted 25 February 2013

This final article is available for use under the terms of the Creative Commons Attribution Non-Commercial 2.0 Licence; see http://bmjopen.bmj.com

For numbered affiliations see end of article.

Correspondence to Dr Aronrag Meeyai; a.meeyai@gmail.com

\section{ABSTRACT}

Objective: To describe changes in reported influenza activity associated with the 2009 H1N1 pandemic in European countries and determine whether there is a correlation between these changes and completeness of national strategic pandemic preparedness.

Design: A retrospective correlational study.

Setting: Countries were included if their national strategic plans had previously been analysed and if weekly influenza-like illness (ILI) data from sentinel networks between week 21, 2006 and week 20, 2010 were more than $50 \%$ complete.

Outcome measures: For each country we calculated three outcomes: the percentage change in ILI peak height during the pandemic relative to the prepandemic mean; the timing of the ILI peak and the percentage change in total cases relative to the prepandemic mean. Correlations between these outcomes and completeness of a country's national strategic pandemic preparedness plan were assessed using the Pearson product-moment correlation coefficient.

Results: Nineteen countries were included. The ILI peak occurred earlier than the mean seasonal peak in 17 countries. In 14 countries the pandemic peak was higher than the seasonal peak, though the difference was large only in Norway, the UK and Greece. Nine countries experienced more total ILI cases during the pandemic compared with the mean for prepandemic years. Five countries experienced two distinct pandemic peaks. There was no clear pattern of correlation between overall completeness of national strategic plans and pandemic influenza outcome measures and no evidence of association between these outcomes and components of pandemic plans that might plausibly affect influenza outcomes (public health interventions, vaccination, antiviral use, public communication). Amongst the 17 countries with a clear pandemic peak, only the correlation between planning for essential services and change in total ILI cases significantly differed from zero: correlation coefficient $(95 \% \mathrm{Cl}) 0.50(0.02,0.79)$.

Conclusions: The diversity of pandemic influenza outcomes across Europe is not explained by the marked variation in the completeness of pandemic plans.

\section{ARTICLE SUMMARY}

Article focus

- Prior to the 2009 influenza pandemic, evaluation of European national strategic pandemic plans revealed wide differences. The H1N1 pandemic declared on 11 June 2009 provided the first opportunity to look for an association between components of these plans and outcomes related to pandemic influenza.

Key messages

- Analysis of influenza-like illness (ILI) activity data from 19 countries revealed important pan-European similarities in pandemic influenza outcomes when compared with seasonal influenza, but also highlighted major and unexpected heterogeneities.

- The diversity of pandemic influenza outcomes across Europe is not explained by the marked variation in the completeness of pandemic plans.

- Future pandemic plans should consider how data on implementation of planning components be recorded and shared, and how formal assessment of the effectiveness of planning components and interventions can be made.

Strengths and limitations of this study

- By evaluating changes in ILI outcomes compared with the prepandemic period it was possible to adjust for wide national variation in ILI reporting rates. Use of detailed prospective prepandemic assessments of national pandemic plans avoided potential biases which post hoc classifications could have been vulnerable to.

- Because only data on pandemic plans and not implementation of these plans are available at a European level, this study can only address the association between plans and outcomes, and not between the implementation of these plans and outcomes.

\section{INTRODUCTION}

The past few years have seen a growing concern over the potential threat of a human influenza pandemic, and while the 
H1N1 pandemic declared on 11 June 2009 was much less severe than had been anticipated, ${ }^{1}$ the report of the 70 paediatric deaths related to H1N1pdm in England highlights the importance of ensuring effective plans are in place. $^{2}$ The H1N1 influenza pandemic provided the first opportunity to look for an association between components of national pandemic strategies and influenza-related outcomes. National and international agencies are attempting to draw lessons from the experience of the H1N1 pandemic. For example, the WHO's Regional Office for Europe has reported preliminary findings based on visits to seven countries, and concluded that pandemic preparedness plans offer benefits enabling countries to respond quickly. ${ }^{3}$ To date, however, there has been no quantitative evaluation of whether these plans translated into measurable effects on influenza-related outcomes. ${ }^{45}$

In 2005, the WHO published a checklist to facilitate preparedness planning to guide countries in the development of national strategic pandemic plans, including measures aimed at reducing transmission and mitigating the consequences. $^{6}$ Most European countries drafted national strategic preparedness plans. ${ }^{7}$ In 2006, we reported our evaluation of European national strategic plans and showed wide differences in the completeness of plans in relation to their inclusion of factors identified by $\mathrm{WHO}$ as important. ${ }^{8}$ Few national strategic plans had been updated since 2006 before the onset of the 2009 pandemic. ${ }^{9}$

In this paper we aim to test the hypothesis that the completeness of national strategic plans for pandemic preparedness as determined against WHO criteria is significantly associated with public health benefit, using data from the 2009 influenza pandemic. To do this we compare the completeness scores from our 2006 analysis against quantitative influenza surveillance data to determine whether a correlation exists between the completeness of a country's national strategic pandemic preparedness plan and observed influenza activity. We focus only on influenza-related outcomes that allow meaningful comparisons between countries.

\section{METHODS}

\section{Data}

Countries were included in the primary analysis if their national strategic plans had previously been analysed and if weekly influenza-like illness (ILI) data from sentinel networks between week 21, 2006 and week 20, 2010 were at least $50 \%$ complete. Nineteen countries met these criteria (figure 1): 17 European Union (EU) countries, and two non-EU countries (Norway and Switzerland). The first 3 years' data (2006-2009) represented three prepandemic influenza seasons and the last year's data (2009-2010) represented the pandemic influenza period.

The ILI data for 17 of 19 countries were accessed through the weekly electronic bulletin published by the European Influenza Surveillance System, ${ }^{10}$ which can be accessed publicly. Weekly ILI data from Italy were accessed through the bulletin of the epidemiological surveillance systems produced by the National Centre of Epidemiology of the Italian National Institute of
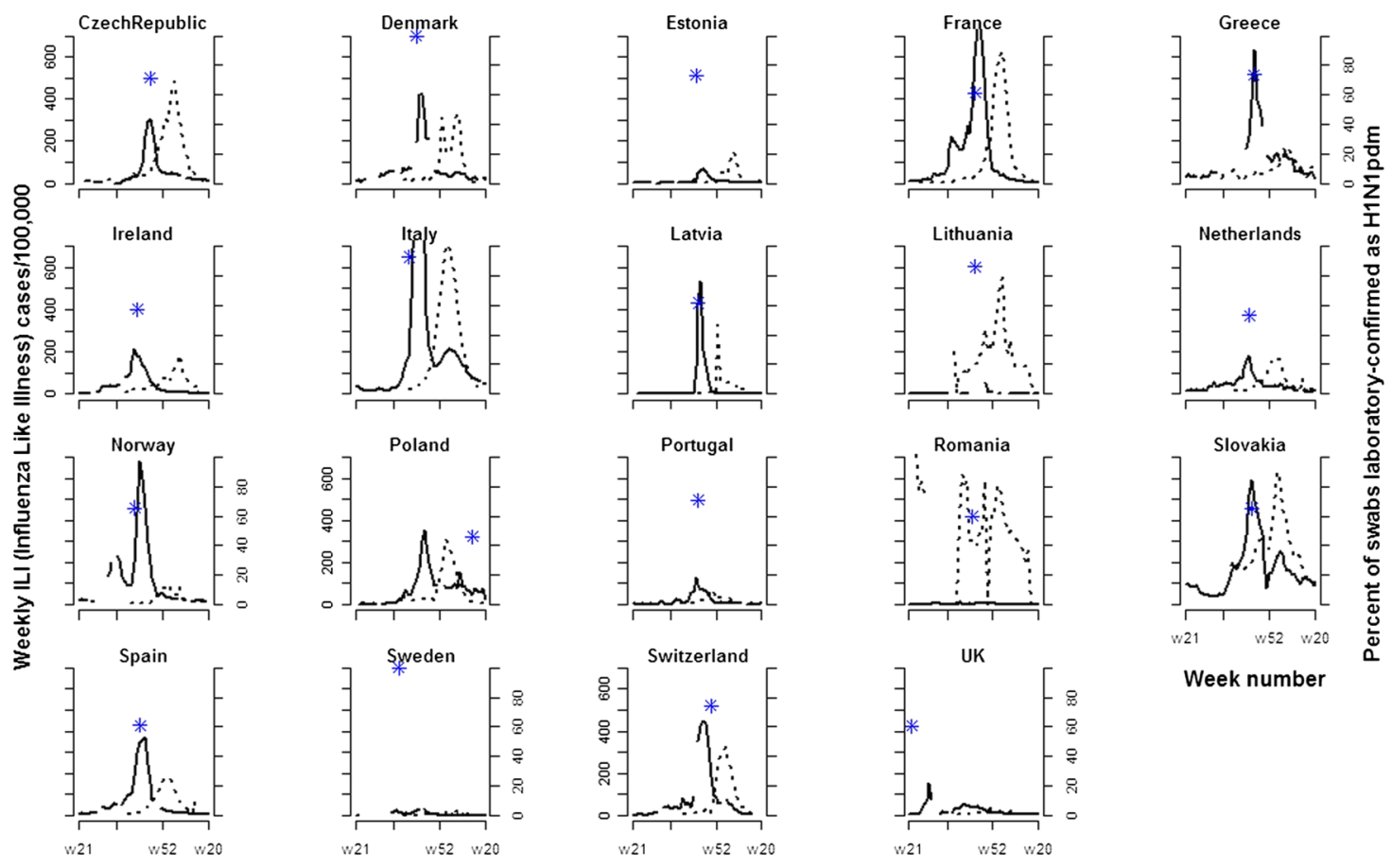

Figure 1 Weekly influenza-like illness (ILI) cases per 100000 for the pandemic year (weeks 21/2009 to 20/2010) (solid line), and the mean of three prepandemic influenza seasons (weeks 21/2006 to 20/2009) (dotted line) in 19 countries in Europe. Stars show the week number where the percentage of swabs from ILI cases which were laboratory-confirmed as being $\mathrm{H} 1 \mathrm{~N} 1 \mathrm{pdm}$ reached a maximum (excluding weeks with fewer than 10 swabs tested). 
Health. ${ }^{11}$ For France, the weekly ILI data were accessed through Réseau Sentinelles France. ${ }^{12}$ Data for the UK were derived as a population-weighted average of data from England, Northern Ireland, Scotland and Wales. We also obtained data from each country for the number of weekly ILI cases laboratory tested for H1N1 pandemic and the number confirmed positive. ${ }^{10}$ However, laboratory testing data are not available in many European countries. We therefore used them to evaluate the validity of the more widely available ILI data, rather than for the primary analysis.

Two clear outliers were identified (Lithuania and Romania) where reported ILI rates in 2009-2010 were much lower than rates from previous years, and ILI incidence patterns differed markedly from those seen elsewhere in Europe. As these differences were thought likely to be due to anomalies in pandemic ILI surveillance in these countries, we performed a sensitivity analysis that excluded these data points.

The score of national strategic plans was obtained for each of the 19 countries. Higher scores represent greater completeness of plans for factors identified by the WHO as important. ${ }^{8}$ The score for each country was categorised into 10 thematic areas. These components corresponded to those used in the evaluation of plans: planning and coordination; surveillance; diagnostic; public health interventions; vaccine; antiviral; health service response; maintenance of essential services; communication and putting plans into action. Scores in each area were expressed as percentages. Quantifiable data and analyses of operational actions taken across countries on the actualisation of plans during the pandemic would have offered insights beyond strategic intentions but are unavailable to date.

\section{Data analysis}

For each country, we calculated the following pandemic influenza outcomes: the percentage change in ILI peak height during the pandemic relative to the mean ILI peak height during the prepandemic period; the timing of the ILI peak expressed both as weeks after the WHO pandemic announcement (11 June 2009) and weeks before the mean of the prepandemic seasonal peaks for each country; and the percentage change in total ILI cases in weeks where ILI data were recorded (irrespective of the number of peaks), relative to the mean for prepandemic years. To ensure this outcome measure was robust to changes in completeness of ILI reporting, while calculating both pandemic and prepandemic ILI cases, we excluded weeks where the country had no data from either the pandemic or the prepandemic period. The prepandemic period was defined as the period before 11 June 2009. When there was more than one peak in a given season or during the pandemic period, we considered only the largest when considering peak height and peak timing. We considered only relative rather than absolute changes in peak height and total cases because ILI reporting rates are known to vary greatly across Europe (figure 1). We considered the timing and size of the ILI peak, in addition to the total number of ILI cases, because delaying the peak and reducing its size would be expected to be associated with public health benefit by providing more time to develop and implement interventions and by reducing peak demand on health services.

To assess correlation between the outcomes (changes in peak height, peak timing and total cases) and the aggregate and category-specific scores of the national strategic plans the Pearson product-moment correlation coefficient and associated 95\% CIs were calculated for each of the outcome-strategic planning combinations.

Both theoretical and empirical research suggests that all three categories of outcomes (changes in peak height, peak timing and cumulative ILI cases) are likely to be affected by control measures that either alter virus transmission, or reduce severity of symptoms in infected hosts. ${ }^{13-17}$ Because all 10 pandemic preparedness categories could plausibly impact on virus transmission or symptom severity under some circumstances, we considered correlations between all outcomes and all category-specific scores. We note that although vaccine deployment was after the peak, vaccination still has the potential to affect total numbers of ILI cases, and for completeness the vaccine planning component was included in all analyses.

\section{RESULTS}

Although ILI reporting rates vary greatly across Europe, clear patterns emerge when we compare 2009-2010 with the prepandemic years (figures 1 and 2). The 2009 pandemic influenza occurred earlier than seasonal influenza in all countries except Lithuania and Romania (where no clear pandemic peaks are evident). In these 17 countries the pandemic peak preceded the seasonal peak by a mean (SD) of 11.47 (4.37) weeks (range 6-24 weeks). Five countries (the UK, Norway, Slovakia, France and Italy) experienced two distinct peaks. All of the 17 countries with pandemic peaks except the Czech Republic, Estonia and Slovakia had a higher peak in the pandemic season than during previous years (mean (SD) percentage change 98.38 (169.30)), though the difference from the prepandemic period was large only in Norway, the UK and Greece. Nine of these 17 countries experienced more total ILI cases during the pandemic compared with prepandemic years (mean (SD) percentage change 22.29 (82.34)). In Norway and Greece the changes were large, with total numbers of cases increasing by $302 \%$ and $100 \%$, respectively. In all countries with major pandemic peaks except the UK they occurred between weeks 40 and 48 . The UK had its major peak in week 29. Ireland, Norway and Sweden also had minor peaks in ILI activity between weeks 24 and 36. In 14 countries, the percentage of laboratorytested swabs which were confirmed as H1N1pdm peaked very close in time to the ILI peak, typically at $40-60 \%$ 
(figure 1). Exceptions were Poland, the UK and Sweden which had anomalous spikes away from the ILI peak in the percentage of tested swabs that were laboratory-confirmed, but local maxima in the percentage laboratory-confirmed very close to the ILI peaks (figure 3).

There was no clear pattern of correlation between the national strategic plans and pandemic mitigation (table 1). In particular, there was no evidence that improved planning for public health interventions, vaccination, antiviral use, communication or an unweighted aggregate of planning components was associated with reduced public health impact of pandemic influenza or delays in the peak timing. For the most important outcome (total ILI cases) the primary analysis of all 19 countries found no evidence of any association between improved planning and reduced ILI cases, and 95\% CIs were inconsistent with moderate or strong negative correlations. Across all 19 countries, 5 of 44 correlation coefficients had 95\% CIs that did not include zero (table 1 ). These corresponded to positive correlations between the change in total ILI cases and three planning scores: health service responses; essential services and the aggregate score. Positive correlations between essential services planning and the change in ILI peak height and between the operational component of the planning score and one measure of pandemic peak timing was also found. In all five cases these suggested that improved planning was associated with a worse outcome: higher or earlier peaks or more cases. Excluding Lithuania and Romania had a large effect on some of the correlations between planning components and the change in ILI outcomes. In some cases these correlations changed sign, but only the correlation between essential services planning and change in ILI outcomes had 95\% CIs that did not include zero. Visual inspection of the scatter plots showed no evidence of a non-linear relationship between planning scores and ILI outcomes (see online supplementary, figures $\mathrm{S} 1-\mathrm{S} 4)$.

\section{DISCUSSION}

Analysis of ILI activity data from 19 countries revealed important pan-European similarities in pandemic influenza outcomes when compared with seasonal influenza, but also highlighted major and unexpected heterogeneities. In particular, Norway, the UK and Greece experienced increases in total cases compared with prepandemic years that were much larger than those seen elsewhere. In the UK this occurred despite the introduction of the National Pandemic Flu Service in July 2009 and recommendations for most patients with influenza-like illness not to consult their general practitioners, a policy that is likely to have resulted in an anomalously low number of reported ILI cases in the second wave.

We found no evidence that the increased impact of the 2009-2010 pandemic in some countries relative to prepandemic years could be explained by shortcomings in national strategic pandemic plans, nor that a reduced impact could be explained by greater completeness of plans. This was true for aggregate measures of planning, specific planning activities that might plausibly be expected to impact a pandemic, and also for less plausible associations. Where evidence of associations were found, in all cases these pointed to improved planning being associated with worse ILI outcomes. While causal mechanisms for such relationships cannot definitively be ruled out, they are not highly plausible. With 88 tests for correlations we would expect between four and five to show significant associations at the $5 \%$ level by chance alone. The five significant associations we found are therefore fully consistent with chance.

The introduction of measures that reduce influenza transmission can, however, under some circumstances, lead to earlier peaks and increasing the effectiveness of transient social-distancing measures can sometimes paradoxically lead to increases in total case numbers. ${ }^{16}$ However, if such mechanisms were operating positive correlations between the change in ILI cases and the
Figure 2 Three influenza-like illness outcomes: changes in peak height and total cases (relative to the three prepandemic seasons) and peak timing (time from the WHO pandemic announcement on 11 June 2009).
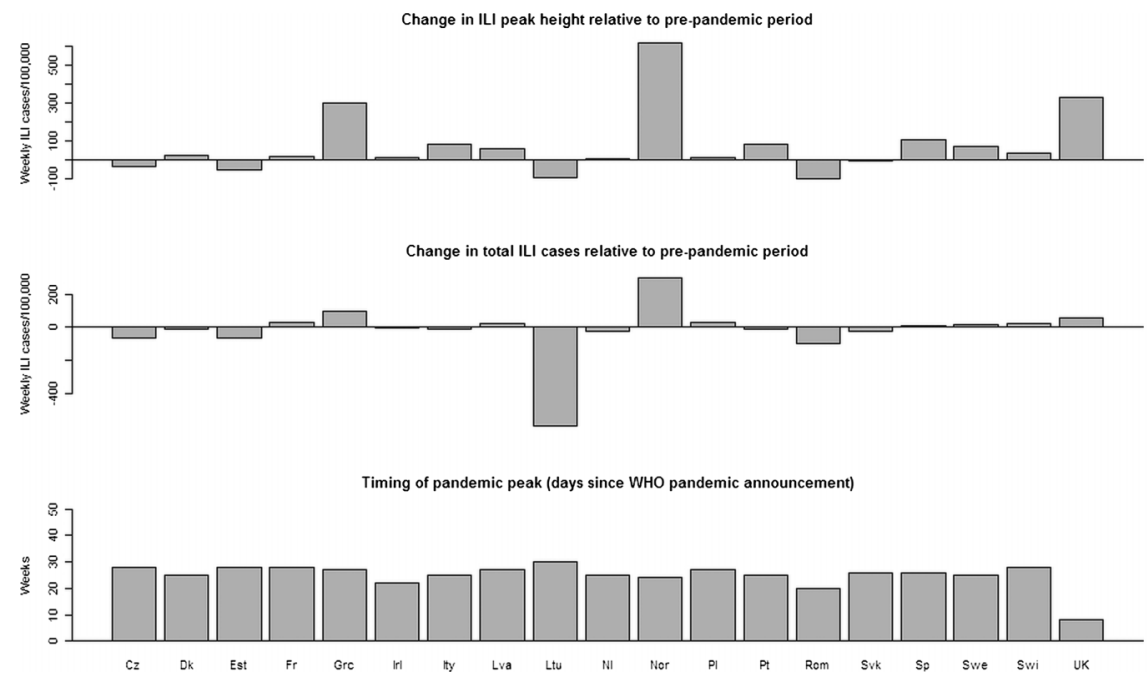

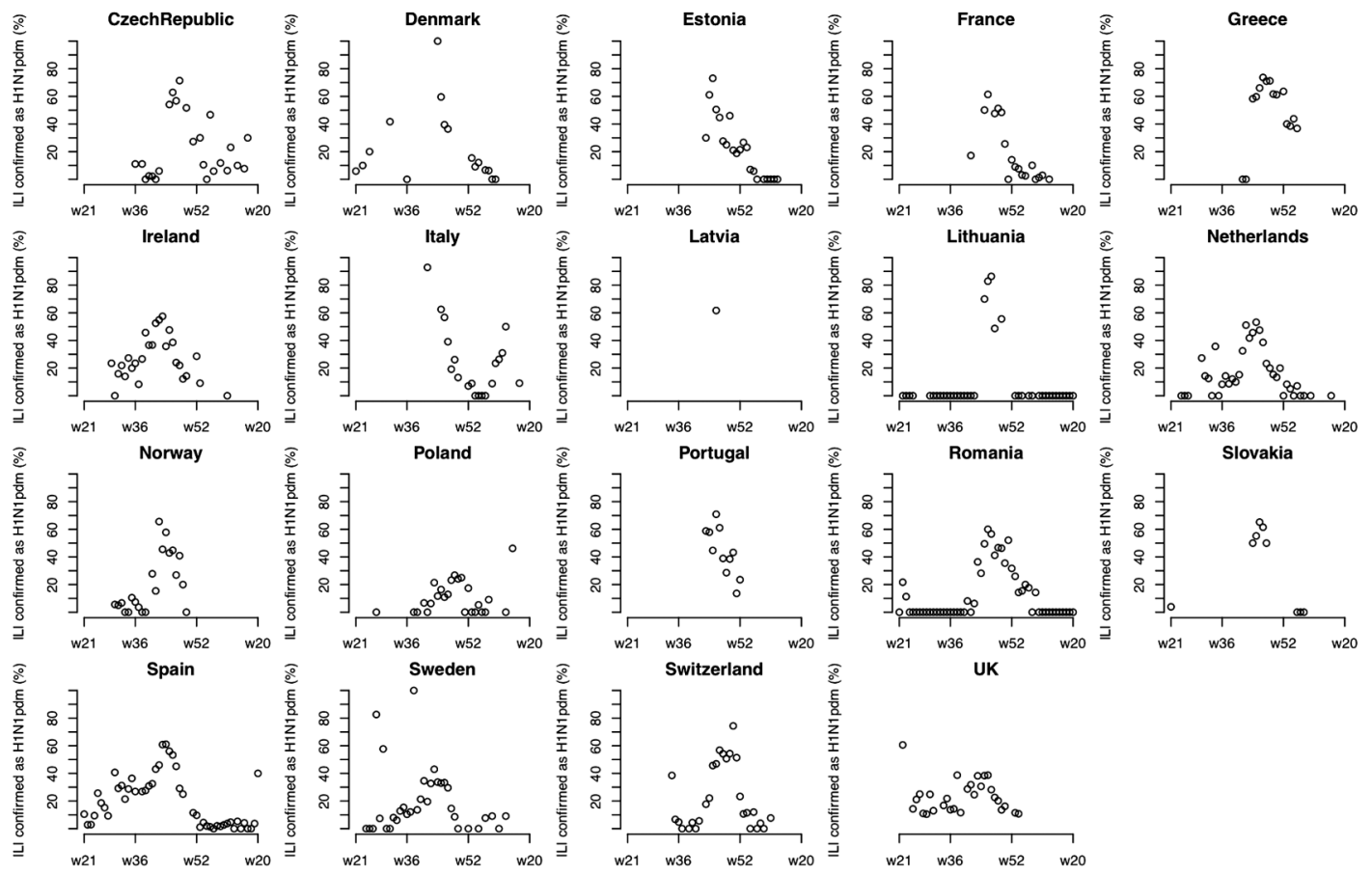

Figure 3 Weely percentage of swabs from influenza-like illness cases which were laboratory-confirmed as being $\mathrm{H} 1 \mathrm{~N} 1 \mathrm{pdm}$ (excluding weeks with fewer than 10 swabs tested).

pandemic planning components public health interventions and antiviral use planning might be expected. In both cases we found only weak and non-significant associations, and these only in the 19-country analysis. When the anomalous ILI data from Lithuania and Romania were removed only planning for essential services was found to be significantly associated with influenza outcomes. Since this category would only be likely to affect ILI outcomes in a severe pandemic for which morbidity and mortality were large enough to threaten the maintenance of essential services, this association seems very unlikely to reflect a causal link. Moreover, our analysis suggests that less complete planning for essential services was associated with public health benefit.

Another possible explanation for the correlations is that countries varied in their propensity to identify pandemic ILI cases relative to seasonal cases. While our analysis allows for national variation in ILI surveillance coverage, this variation is assumed to be constant over time. A greater likelihood of detecting ILI cases in pandemic relative to non-pandemic years in well-prepared countries could plausibly account for some of the associations seen. This could happen, for example, if countries with improved public communication systems encouraged possible cases to seek medical attention.

While these findings do not preclude important beneficial effects of planning activities on influenza outcomes, they do indicate that the marked variation in completeness of pandemic plans across Europe is unable to explain most of the diversity in pandemic outcomes. In particular, no evidence was found that improved planning was associated with reductions in ILI cases, reduction in the ILI peak height, or delays in the pandemic peak. Given the body of theoretical and empirical evidence that a number of planning components, if implemented, can substantially reduce transmission, ${ }^{17-20}$ and the large variation in these planning components across the 17 countries, these results are surprising. However, they hold true both when planning scores are considered in aggregate and also when themes that plausibly impact directly on transmission are analysed. There are a number of possible explanations: first, effective components of pandemic plans may not have been implemented; second, components of pandemic plans may have been implemented but could have been less effective than theoretical studies suggested; third, it is possible that country-wide variation in pandemic outcomes was dominated by factors unrelated to control measures such as demographics and prior immunity. It is also possible that the summary measure of planning completeness we have used fails to reflect important heterogeneities in the effectiveness of specific components. A measure of planning completeness that gives higher weights to more effective components may have yielded different results. Assigning such weights, however, would be problematic.

Our study has some limitations. First, we could retrieve sufficient data from only 19 countries including only 17 of the $27 \mathrm{EU}$ member states. Second, correlation is not causation and, equally, lack of correlation is not lack of causation. A causal link between pandemic planning and H1N1pdm outcomes is possible, but may be masked by variation in environmental, demographic, behavioural and genetic factors that might have had larger 
Table 1 Pearson's product-moment correlation coefficients (95\% Cls) for categories of pandemic preparedness and three influenza-like illness (ILI) outcomes*

\begin{tabular}{|c|c|c|c|c|}
\hline & $\begin{array}{l}\text { Change in ILI peak } \\
\text { height relative to } \\
\text { prepandemic period }\end{array}$ & $\begin{array}{l}\text { Change in total ILI } \\
\text { cases relative to } \\
\text { prepandemic period }\end{array}$ & $\begin{array}{l}\text { Timing of pandemic } \\
\text { peak } 1 \text { (weeks since } \\
\text { WHO pandemic } \\
\text { announcement) }\end{array}$ & $\begin{array}{l}\text { Timing of pandemic } \\
\text { peak } 2 \text { (weeks before } \\
\text { mean week of the } \\
\text { prepandemic peak) }\end{array}$ \\
\hline $\begin{array}{l}\text { Aggregate } \\
\text { planning score }\end{array}$ & $\begin{array}{l}0.17(-0.34 \text { to } 0.60) \\
0.24(-0.24 \text { to } 0.63)\end{array}$ & $\begin{array}{l}0.12(-0.38 \text { to } 0.57) \\
0.49(0.05 \text { to } 0.77)\end{array}$ & $\begin{array}{l}-0.34(-0.70 \text { to } 0.17) \\
-0.37(-0.71 \text { to } 0.10)\end{array}$ & $\begin{array}{l}0.43(-0.06 \text { to } 0.76) \\
0.32(-0.15 \text { to } 0.68)\end{array}$ \\
\hline $\begin{array}{l}\text { Planning and } \\
\text { coordination }\end{array}$ & $\begin{array}{l}0.25(-0.26 \text { to } 0.65) \\
0.22(-0.26 \text { to } 0.61)\end{array}$ & $\begin{array}{l}0.18(-0.33 \text { to } 0.61) \\
0.37(-0.10 \text { to } 0.70)\end{array}$ & $\begin{array}{l}-0.24(-0.64 \text { to } 0.28) \\
-0.30(-0.67 \text { to } 0.17)\end{array}$ & $\begin{array}{l}0.44(-0.05 \text { to } 0.76) \\
0.19(-0.29 \text { to } 0.59)\end{array}$ \\
\hline Surveillance & $\begin{array}{l}-0.13(-0.58 \text { to } 0.37) \\
-0.02(-0.47 \text { to } 0.44)\end{array}$ & $\begin{array}{r}-0.15(-0.59 \text { to } 0.36) \\
0.35(-0.12 \text { to } 0.70)\end{array}$ & $\begin{array}{l}-0.17(-0.60 \text { to } 0.34) \\
-0.28(-0.65 \text { to } 0.20)\end{array}$ & $\begin{array}{l}0.35(-0.16 \text { to } 0.71) \\
0.13(-0.34 \text { to } 0.56)\end{array}$ \\
\hline Diagnostic & $\begin{array}{l}-0.04(-0.51 \text { to } 0.45) \\
-0.11(-0.54 \text { to } 0.36)\end{array}$ & $\begin{array}{r}-0.21(-0.63 \text { to } 0.30) \\
0.31(-0.17 \text { to } 0.67)\end{array}$ & $\begin{array}{r}0.08(-0.42 \text { to } 0.54) \\
-0.06(-0.50 \text { to } 0.41)\end{array}$ & $\begin{array}{r}0.08(-0.42 \text { to } 0.54) \\
-0.01(-0.46 \text { to } 0.45)\end{array}$ \\
\hline $\begin{array}{l}\text { Public health } \\
\text { interventions }\end{array}$ & $\begin{array}{l}-0.05(-0.52 \text { to } 0.44) \\
-0.03(-0.48 \text { to } 0.43)\end{array}$ & $\begin{array}{r}-0.17(-0.60 \text { to } 0.34) \\
0.30(-0.18 \text { to } 0.66)\end{array}$ & $\begin{array}{r}0.00(-0.48 \text { to } 0.48) \\
-0.07(-0.51 \text { to } 0.39)\end{array}$ & $\begin{array}{r}-0.02(-0.50 \text { to } 0.46) \\
0.10(-0.37 \text { to } 0.53)\end{array}$ \\
\hline Vaccines & $\begin{array}{l}0.17(-0.34 \text { to } 0.60) \\
0.24(-0.24 \text { to } 0.62)\end{array}$ & $\begin{array}{r}0.21(-0.30 \text { to } 0.63) \\
0.3(-0.15 \text { to } 0.68)\end{array}$ & $\begin{array}{l}-0.40(-0.74 \text { to } 0.10) \\
-0.45(-0.75 \text { to } 0.01)\end{array}$ & $\begin{array}{l}0.42(-0.08 \text { to } 0.75) \\
0.18(-0.30 \text { to } 0.59)\end{array}$ \\
\hline Antiviral drugs & $\begin{array}{l}0.26(-0.26 \text { to } 0.66) \\
0.24(-0.24 \text { to } 0.61)\end{array}$ & $\begin{array}{l}0.15(-0.35 \text { to } 0.59) \\
0.39(-0.08 \text { to } 0.71)\end{array}$ & $\begin{array}{l}-0.12(-0.57 \text { to } 0.38) \\
-0.15(-0.57 \text { to } 0.32)\end{array}$ & $\begin{array}{l}0.32(-0.19 \text { to } 0.70) \\
0.28(-0.19 \text { to } 0.65)\end{array}$ \\
\hline $\begin{array}{l}\text { Health service } \\
\text { response }\end{array}$ & $\begin{array}{l}0.15(-0.26 \text { to } 0.66) \\
0.24(-0.24 \text { to } 0.63)\end{array}$ & $\begin{array}{l}0.13(-0.37 \text { to } 0.57) \\
0.56(0.14 \text { to } 0.81)\end{array}$ & $\begin{array}{l}-0.30(-0.68 \text { to } 0.21) \\
-0.37(-0.71 \text { to } 0.10)\end{array}$ & $\begin{array}{l}0.45(-0.04 \text { to } 0.76) \\
0.26(-0.22 \text { to } 0.64)\end{array}$ \\
\hline $\begin{array}{l}\text { Essential } \\
\text { services }\end{array}$ & $\begin{array}{l}0.47(-0.01 \text { to } 0.78) \\
0.57(0.15 \text { to } 0.81)\end{array}$ & $\begin{array}{l}0.50(0.02 \text { to } 0.79) \\
0.48(0.03 \text { to } 0.77)\end{array}$ & $\begin{array}{l}-0.36(-0.71 \text { to } 0.15) \\
-0.31(-0.67 \text { to } 0.17)\end{array}$ & $\begin{array}{l}0.27(-0.24 \text { to } 0.66) \\
0.38(-0.09 \text { to } 0.71)\end{array}$ \\
\hline Communication & $\begin{array}{l}0.04(-0.45 \text { to } 0.51) \\
0.13(-0.34 \text { to } 0.55)\end{array}$ & $\begin{array}{r}-0.02(-0.49 \text { to } 0.47) \\
0.35(-0.12 \text { to } 0.70)\end{array}$ & $\begin{array}{l}-0.34(-0.71 \text { to } 0.17) \\
-0.32(-0.67 \text { to } 0.16)\end{array}$ & $\begin{array}{l}0.18(-0.33 \text { to } 0.61) \\
0.32(-0.15 \text { to } 0.68)\end{array}$ \\
\hline $\begin{array}{l}\text { Operational } \\
\text { (putting plans } \\
\text { into action) }\end{array}$ & $\begin{array}{l}0.22(-0.29 \text { to } 0.63) \\
0.36(-0.11 \text { to } 0.70)\end{array}$ & $\begin{array}{l}0.25(-0.26 \text { to } 0.65) \\
0.40(-0.07 \text { to } 0.72)\end{array}$ & $\begin{array}{l}-0.45(-0.77 \text { to } 0.04) \\
-0.38(-0.71 \text { to } 0.08)\end{array}$ & $\begin{array}{l}0.45(-0.04 \text { to } 0.76) \\
0.49(0.05 \text { to } 0.77)\end{array}$ \\
\hline
\end{tabular}

impacts. $^{2} 2122$ These merit further investigation. Second, we analysed ILI data rather than laboratory-confirmed H1N1 pandemic cases because the quantity of laboratoryconfirmed cases was insufficient to enable meaningful comparisons. Standardised data on related outcomes such as severe pneumonia and attributable mortality are not available across European countries. Although ILI is an imperfect outcome that may be affected by changing patterns of healthcare-seeking behaviour, and case definitions vary across Europe, ${ }^{23}$ we found that in most countries it peaked at the same time as the proportion of ILI cases that were laboratory-confirmed, a result consistent with prepandemic findings. This provides reassurance that ILI peaks are not simply artefacts of the surveillance system. Additionally, to enable meaningful betweencountry comparisons robust to the vagaries of national ILI reporting, we considered only summary measures relating to peak timing, or changes in ILI outcomes relative to prepandemic years. This should largely prevent distortions attributable to marked country-level variation in ILI reporting systems. Finally, we considered only pandemic plans and not implementation and therefore our analysis only addresses the stated research question which concerns the relationship between plans and outcomes. It is currently unclear how a documented intention to implement control measures is translated into practice and in the absence of such detailed implementation data we cannot address important questions concerning the relationship between plans and implementation, and implementation and outcomes. Evaluating the implementation of pandemic plans is an important area for future research, one that others are attempting, ${ }^{3}$ and it will be important to evaluate both effectiveness and costeffectiveness of specific components of pandemic plans, such as antiviral use, ${ }^{24}$ vaccination ${ }^{25}$ and social distancing measure. ${ }^{16}$ Model-based analyses may help in this matter and also enable us to begin to make quantitative assessments of the importance of contact patterns (and 
the effect of school closure on these), and atmospheric conditions. ${ }^{26-28}$ Model-based analysis may also help overcome deficiencies in surveillance data: two reconstructions of the pandemic within the UK suggested a very different pattern to that seen in the crude ILI data (figure 1), and suggested that the second peak was comparable in size to the first. ${ }^{27}{ }^{28}$ However, a sensitivity analysis (data not shown) found that our overall conclusions would not have changed had we considered the second UK peak to be the major one.

Drawing lessons from the 2009 influenza pandemic is challenging and likely to be the subject of research for years to come. One seems clear, however: for lessons to be drawn through comparative analyses across countries, surveillance data need to be robust, timely and systematic. Our research highlights the lack of complete or consistent influenza surveillance data across Europe, ${ }^{29}$ and the absence of in-built mechanisms for evaluating the effectiveness or otherwise of pandemic plans. Given that interventions have the potential to make outcomes worse as well as better, and that responses to previous pandemics appear to have been far from optimal, ${ }^{17}$ this is concerning. A pandemic surveillance model that combines surveillance for non-specific syndromes (such as ILI) with consistent laboratory testing for a subset of cases has been advocated. ${ }^{30}$ As well as conserving resources when surveillance systems are under considerable stress, this has the potential to facilitate comparative analyses and provide greater lesson-learning opportunities.

Finally, to help ensure the international response to future pandemics has a sound evidence base that effectively draws upon past experience, we suggest that future pandemic plans should consider how data on implementation of planning components can be recorded and shared, and how formal assessments of the effectiveness of interventions can be made.

\section{Author affiliations}

${ }^{1}$ Department of Epidemiology, Faculty of Public Health, Mahidol University, Bangkok, Thailand

${ }^{2}$ Communicable Diseases Policy Research Group (CDPRG), London School of Hygiene and Tropical Medicine, Faculty of Public Health, Mahidol University, Bangkok, Thailand

${ }^{3}$ Mahidol-Oxford Tropical Medicine Research Unit (MORU), Faculty of Tropical Medicine, Mahidol University, Bangkok, Thailand

${ }^{4}$ Centre for Clinical Vaccinology and Tropical Medicine, Nuffield Department of Clinical Medicine, University of Oxford, Oxford, UK

Contributors AM, BSC and RC designed the study. AM collected the data. AM performed the analysis and wrote the first draft of the paper. BSC and RC contributed to writing the paper. All authors read and approved the final manuscript.

Funding This research received no specific grant from any funding agency in the public, commercial or not-for-profit sectors.

Competing interest None.

Provenance and peer review Not commissioned; externally peer reviewed.

Data sharing statement All influenza data are publicly available (see references). The pandemic preparedness scores are available at our group website: http://www.cdprg.org/publications.php.

\section{REFERENCES}

1. Presanis AM, De Angelis D, The New York City Swine Flu Investigation Team, et al. The severity of pandemic H1N1 influenza in the United States, from April to July 2009: a bayesian analysis. PLOS Med 2009;6:e1000207.

2. Sachedina N, Donaldson LJ. Paediatric mortality related to pandemic influenza A H1N1 infection in England: an observational population-based study. Lancet 2010;376:1846-52.

3. Update on evaluation of the response to pandemic (H1N1) 2009. WHO: regional office for Europe. http://www.euro.who.int/en/what-we-do/ health-topics/diseases-and-conditions/influenza/pandemic-h1n1-2009/ whoeurope-news-and-updates/update-on-evaluation-of-the-responseto-pandemic-h1n1-2009 (accessed 9 Nov 2012).

4. Report on evaluation of the management of $\mathrm{H} 1 \mathrm{~N} 1$ influenza in 2009-2010 in the EU (2010/2153(INI)). Committee on the Environment, Public Health and Food Safety. http://www.europarl. europa.eu/sides/getDoc.do?type=REPORT\&reference=A72011-0035\&language $=E N$ (accessed 9 Nov 2012)

5. Animal and pandemic influenza: a framework for sustaining momentum. Fifth Global Progress Report 2010. United Nations System Influenza Coordination and the World Bank. http:// un-influenza.org/files/Global\%20Progress\%20Report\%202010.pdf (accessed 9 Nov 2012)

6. WHO Checklist for influenza epidemic preparedness. WHO/CDS/ CSR/GIP/2005.4. Geneva: World Health Organization, 2005.

7. Pandemic influenza preparedness in the EU: Technical Report I January 2007. ECDC. http://www.ecdc.europa.eu/en/publications/ Publications/0701_TER_Pandemic_Influenza_Preparedness.pdf (accessed 9 Nov 2012).

8. Mounier-Jack S, Coker RJ. How prepared is Europe for pandemic influenza? Analysis of national plans. Lancet 2006;367:1405-11.

9. Pandemic preparedness plans. ECDC. http://www.ecdc.europa.eu/en/ healthtopics/pandemic_preparedness/national_pandemic_ preparedness plans/Pages/national_pandemic preparedness_plans. aspx (accessed 9 Nov 2012).

10. European Influenza Surveillance System (EISS). ECDC. http://ecdc. europa.eu/en/healthtopics/seasonal_influenza/epidemiological_data/ Pages/archive_weekly_electronic_bulletins.aspx (accessed 9 Nov 2012).

11. The National Centre of Epidemiology of the Italian National Institute of Health. Istituto Superiore di Sanità. http://www.iss.it/iflu/ (accessed 9 Nov 2012)

12. Influenza-like illness. Réseau Sentinelles. http://websenti.b3e.jussieu. $\mathrm{fr} /$ sentiweb/index.php?rub=67\&mal=3 (accessed 12 Nov 2011).

13. Halloran ME, Ferguson NM, Eubank S, et al. Modeling targeted layered containment of an influenza pandemic in the United States. Proc Natl Acad Sci USA 2008:105:4639-44.

14. Hatchett RJ, Mecher CE, Lipsitch M. Public health interventions and epidemic intensity during the 1918 influenza pandemic. Proc Natl Acad Sci USA 2007;104:7582-7.

15. Glass RJ, Glass LM, Beyeler WE, et al. Targeted social distancing design for pandemic influenza. Emerg Infect Dis 2006;12:1671-81

16. Bootsma MC, Ferguson NM. The effect of public health measures on the 1918 influenza pandemic in U.S. cities. Proc Natl Acad Sci USA 2007;104:7588-93.

17. Ferguson NM, Cummings DA, Fraser $\mathrm{C}$, et al. Strategies for mitigating an influenza pandemic. Nature 2006;442:448-52.

18. Shaman J, Pitzer VE, Viboud C, et al. Absolute humidity and the seasonal onset of influenza in the continental United States. PLoS Biol 2010;8:e1000316.

19. Ghani AC, Baguelin M, Griffin J, et al. The early transmission dynamics of H1N1pdm influenza in the United Kingdom. PLoS Curr 2009;1:RRN1130. [revised 13 Jun 2010].

20. Halloran ME, Hayden FG, Yang Y, et al. Antiviral effects on influenza viral transmission and pathogenicity: observations from household-based trials. Am J Epidemiol 2007;165:212-21.

21. Goldstein $\mathrm{E}$, Dushoff $\mathrm{J}, \mathrm{Ma} J$, et al. Reconstructing influenza incidence by deconvolution of daily mortality time series. Proc Natl Acad Sci USA 2009:106:21825-9.

22. Aguilera JF, Paget WJ, Mosnier A, et al. Heterogeneous case definitions used for the surveillance of influenza in Europe. Eur $J$ Epidemiol 2003:18:733-6.

23. Paget J, Marquet R, Meijer A, et al. Influenza activity in Europe during eight seasons (1999-2007): an evaluation of the indicators used to measure activity and an assessment of the timing, length and course of peak activity (spread) across Europe. BMC Infect Dis 2007;7:141.

24. Siddiqui MR, Edmunds WJ. Cost-effectiveness of antiviral stockpiling and near-patient testing for potential influenza pandemic. Emerg Infect Dis 2008;14:267-74. 
25. Nishiura $\mathrm{H}$, Oshitani $\mathrm{H}$. Effects of vaccination against pandemic (H1N1) 2009 among Japanese children. Emerg Infect Dis 2011;17:746-7.

26. Flasche S, Hens N, Boëlle P-Y, et al. Different transmission patterns in the early stages of the influenza $A(\mathrm{H} 1 \mathrm{~N} 1)$ pandemic: a comparative analysis of 12 European countries. Epidemics 2011;3:125-33.

27. Birrell PJ, Ketsetzis G, Gay NJ, et al. Bayesian modeling to unmask and predict influenza $\mathrm{A} / \mathrm{H} 1 \mathrm{~N} 1 \mathrm{pdm}$ dynamics in London. Proc Natl Acad Sci USA 2011;108:18238-43.
28. Baguelin $M$, Hoek $A J$, Jit $M$, et al. Vaccination against pandemic influenza $\mathrm{A} / \mathrm{H} 1 \mathrm{~N} 1 \mathrm{v}$ in England: a real-time economic evaluation. Vaccine 2010;28:2370-84.

29. Johnson $H$, Meeyai A, Coker R. Potential for greater coherence in European influenza surveillance. Eur J Public Health 2010;20:488-9.

30. Lipsitch M, Hayden FG, Cowling BJ, et al. How to maintain surveillance for novel influenza $\mathrm{A} \mathrm{H} 1 \mathrm{~N} 1$ when there are too many cases to count. Lancet 2009;374:1209-11. 